\title{
A Closer Look at the Pangasinan Verbal Affixes maN- and oN- *
}

\author{
Francisco C. Rosario, Jr. ${ }^{* *}$ \\ (University of the Philippines Diliman, Philippines)
}

\begin{abstract}
The main objective of this paper is to present a simple description and discussion of the semantic and grammatical functions of the Pangasinan verbal affixes maN- and oN-. The semantic description of the functions of these Pangasinan verbal affixes was based on the meanings derived from the combination of the verbal affix and a list of compatible verb roots. Verb roots that are semantically related were also identified and classified to present an evidence that support the view that in particular semantic classes of verb roots, the root-affix correspondence is regular. The grammatical functions, on the other hand, were determined based on the type of arguments selected by the verbs, which were derived using the two verbal affixes. At least 370 verb roots were analyzed to identify the semantic and grammatical functions of these verbal affixes.
\end{abstract}

Keywords: Philippine language, Pangasinan, morphology, verbal affixes

\section{Introduction}

In most linguistic analysis of the Pangasinan language ${ }^{(1)}$, the description and discussion on verbs and verbal affixes are usually focused on the classification of verbal affixes based on aspectual forms (Mendoza, 1965), markers and verbal affixes that constitute the Pangasinan focus system (Magat, 1970), and categories of verbs based on what they focus with the corresponding affixes, i.e. whether the affixes are used to form the subjective or objective verbal forms (Fidel de Amurrio, 1970). Verbs, on the other hand, are classified based on transitivity, mode, focus, and voice (Benton, 1970) and subcategorized based on the number and types of arguments that co-occur with the verb (Rosario, 2013). Though these types of description and classification of verbs and verbal affixes can be useful in

\footnotetext{
* This paper is based on a portion of my master's thesis titled Subcategorization of Pangasinan Verbs.

** Francisco C. Rosario, Jr.: Assistant Professor, Department of Linguistics, College of Social Sciences and Philosophy, University of the Philippines Diliman, Quezon City, 1101, Philippines. E-mail: fcrosariojr@ gmail.com.

(1) The Pangasinan language is one of the major languages in the Philippines and is being used and spoken in Pangasinan, a province located in the north-western region of the country. According to Ethnologue, it belongs to the following classification of languages: Austronesian, Malayo-Polynesian, Northern Luzon, Meso-Cordilleran, South-Central Cordilleran, Southern Cordilleran, West Southern Cordilleran (Simons \& Fennig, 2017).
} 
providing a general description of the language, one can also prove it is quite inadequate.

In his description of the Inibaloi verbal affixes, Ballard (1973:181-184) provided the following situations to show that a closer look at verbs and verbal affixes is needed aside from the above-mentioned and usual classification and description:

(a) A large number of roots occur with two different affixes and yet with no corresponding grammatical difference in the clause...

(b) .... the same affix-root combination will have two or more meanings, and the clauses containing these verbs will have contrasting situational role structures...

(c) .... the meaning of an affixed verb cannot be predicted if one knows the meaning of another of its affixed forms.

Ballard's observation on the Inibaloi language can also be observed in the Pangasinan language. For example, sentences (1a) and (1b) below do not show any grammatical distinction.

\begin{tabular}{|c|c|c|c|}
\hline \multirow{2}{*}{\multicolumn{4}{|c|}{$\begin{array}{l}\text { (1a) } \text { Inminom } \\
\text { ?<inm>inom }\end{array}$}} \\
\hline & & & \\
\hline ?<Prf.AgF>drink & 1Sg.ABS & CNMarkSg & water \\
\hline \multicolumn{4}{|l|}{ 'I drank water.' } \\
\hline (1b) Naninom & ak & ya & danom \\
\hline nan-inom & & & \\
\hline Prf.AgF-drink & 1Sg.ABS & CNMarkSg & water \\
\hline 'I drank water.' & & & \\
\hline
\end{tabular}

Both sentences mean 'I drank water' in English and the use of the focus affixes nan- and -inm- does not signal any grammatical contrast in the sense that the number and type of arguments involved in the two sentences are the same.

There are instances, too, when the use of verbal affixes changes the grammatical composition of the sentence, as can be observed in sentences (2a) and (2b).

$\begin{array}{lllll}\text { (2a) } & \begin{array}{l}\text { Binmatik } \\ \text { B }<\text { inm>atik }\end{array} & \text { imay } & \text { ogaw } & \\ & & & & \\ \text { <Prf.AgF>run } & \text { FCNMarkSg } & \text { child } & & \\ \begin{array}{c}\text { The child ran.' } \\ \text { (2b) Nanbatik }\end{array} & \text { imay } & \text { ogaw } & \text { ya } & \text { tinapay } \\ \text { nan-batik } & & & & \\ \text { Prf.AgF-run } & \text { FCNMarkSg } & \text { child } & \text { Det } & \text { bread }\end{array}$

Both sentences (2a) and (2b) show grammatical contrast - the verb binmatik in the first sentence only requires a grammatical subject ogaw 'child' while the verb nanbatik in second sentence would require both the grammatical subject ogaw 'child' and object tinapay 'bread'. A native speaker of the language can also spot the semantic distinction 


\section{Francisco C. Rosario, Jr.}

between binmatik 'ran' and nanbatik 'ran away with something'. One is intransitive and the other is transitive.

Unpredictability can also be observed in terms of the affix-root correspondence. In the case of the verb root inom 'drink', the verb root can be conjugated with either nan- or -inmbut the verb root apiger 'fix' can accept the affix nan- but not the affix -inm-. This seemingly random and chaotic relationship between the verbal affixes and roots is a common observation not only in the Pangasinan language but also in other Philippine languages. Quoting the authors of Tagalog Reference Grammar Paul Schachter and Fe Otanes (1972:283), "no general rules can be given for the occurrence or nonoccurrence of a base with any particular major affix".

These observations on Pangasinan verb morphology, as well as other Philippine languages served as the motivation of the researcher to take a closer look at the semantic and grammatical functions of the Pangasinan verbal affixes, particularly the affixes maNand oN-which are usually classified as agent focus affixes. A description of these affixes, not only limited to the classification based on their aspectual forms, voice, and focus system will provide a deeper understanding of the linguistic features of the language which will be very helpful in the teaching and learning of the language.

\section{Methodology}

To determine the semantic functions of the Pangasinan verbal affixes, I have tested several verb roots to identify which verbal affixes they can take. The grammatical and semantic functions of each affix were determined based on how these affixes were used in combination with the verb roots.

Firstly, the verb roots were analyzed to see whether a particular semantic class of verb roots allows a regular affix-root correspondence. This is done to present an alternative view that there is regularity in terms of the distribution of some verb roots and affixes, particularly in the Pangasinan language. The types of arguments, whether internal or external ${ }^{(\mathbb{1}}$, were also taken into consideration, including the semantic role assigned by the derived Pangasinan verb to these arguments ${ }^{2}$. Lastly, since some verb roots can be conjugated with both affixes, I also identified the semantic contrasts of the two verbal affixes by looking at the semantic difference of the derived verbs with the same root, e.g. manakdol vs. onakdol.

At least 370 verb roots were used and analyzed to provide a description of the

\footnotetext{
(1) External (or subject) arguments refer to the grammatical subject while internal (or non-subject) arguments refer to the complements of the verb.

(2) In this paper, the term focus refers to the relationship between the verb and the subject, and uses the following focus: agent, theme, beneficiary, recipient, location, and instrument.
} 
A Closer Look at the Pangasinan Verbal Affixes maN- and oN-

grammatical and semantic functions of the affixes. Fidel de Amurrio (1970) and Richard Benton (1971) were used as main references especially on how these two Pangasinan verbal affixes were described. I also used my intuition and knowledge as a native of the language to provide evidence or support additional observations I made, which were discussed in the succeeding sections of this paper.

\section{The Pangasinan Verbal Affixes maN- and oN-: Forms and Functions ${ }^{(1)}$}

Table 1 presents the aspectual forms of these verbal affixes including the morphophonemic changes involved when these affixes are used along with certain verb roots. The maN- affix usually becomes [mam] when the root starts with a bilabial sound. The affix becomes [may] when the affix is attached to a root that starts with a velar sound. Elsewhere, the form [man] is used. It can be observed that the affix oN-also undergoes the same morphophonemic changes and processes as the verbal affix maN-.

Table 1. Aspectual forms of the Pangasinan verbal affixes $m a N$ - and $o N$ -

\begin{tabular}{|c|c|c|c|}
\hline Infinitive & Perfective & Imperfective & Contemplative \\
\hline$m a N-+$ root & $\begin{array}{l}n a N-\text { + root; } \\
\text { regressive nasal } \\
\text { assimilation occurs }\end{array}$ & $\begin{array}{l}m a N-+\left(\mathrm{C}_{1}\right) \mathrm{V}_{1} \\
\text { reduplication + root; } \\
\text { regressive nasal } \\
\text { assimilation occurs }\end{array}$ & $\begin{array}{l}m a N-+ \text { root; } \\
\text { regressive nasal } \\
\text { assimilation occurs }\end{array}$ \\
\hline $\begin{array}{l}\text { ames 'bathe' } \\
\text { balkot 'wrap' }\end{array}$ & $\begin{array}{l}\text { nanames } \\
\text { nambalkot }\end{array}$ & $\begin{array}{l}\text { manaames } \\
\text { mambabalkot }\end{array}$ & $\begin{array}{l}\text { manames } \\
\text { mambalkot }\end{array}$ \\
\hline$o N-+$ root & $-i n m-+$ root & $\begin{array}{l}o N-+\left(\mathrm{C}_{1}\right) \mathrm{V}_{1}+\text { root; } \\
\text { regressive nasal } \\
\text { assimilation occurs }\end{array}$ & $\begin{array}{l}o N-+ \text { root; } \\
\text { regressive nasal } \\
\text { assimilation occurs }\end{array}$ \\
\hline $\begin{array}{l}\text { irong 'sit' } \\
\text { sabi 'arrive' }\end{array}$ & $\begin{array}{l}\text { inmirong } \\
\text { sinmabi }\end{array}$ & $\begin{array}{l}\text { oniirong } \\
\text { onsasabi }\end{array}$ & $\begin{array}{l}\text { onirong } \\
\text { onsabi }\end{array}$ \\
\hline
\end{tabular}

According to Fidel de Amurrio (1970), the affixes maN- and oN- are used to form the subjective verbal forms. The subjective verbal forms are used if the focus of the construction is the actor or the doer of the action. Benton (1971:124) also made a similar observation that these verbal affixes are used in active constructions where "the initiator of

\footnotetext{
(1) Abbreviations used in this paper: - = morpheme boundary; $\langle$ space $>=$ word boundary; = = clitic boundary; 1 = first person; $2=$ second person; 3 = third person; $\mathrm{ABS}=$ absolutive; $\mathrm{Ag}=$ agent $\mathrm{CN}=$ common noun; Cont = contemplative; F = focus; GEN = genitive; Incl = inclusive; $\mathrm{LNK}=$ linker; Loc = location; Mark = marker; $\mathrm{OBL}=$ oblique $; \mathrm{Prf}=$ perfective $; \mathrm{Pl}=$ plural $; \mathrm{PN}=$ personal noun $; \mathrm{Sg}=$ singular; $\mathrm{Th}=$ theme.
} 


\section{Francisco C. Rosario, Jr.}

the action (if any) is the subject". A closer look at these verbal affixes, however, reveals that the grammatical subject in the constructions is not always the doer or initiator of the action. If the semantic role of the subject argument is considered, we will find specific forms in which the grammatical subject is something that experiences the action or undergoes a change of state.

The following section presents the semantic classes of verb roots that allow a regular affix-root correspondence. It is followed by the different categories of derived Pangasinan verbs based on the types of arguments that co-occur with the verb, as well as the semantic role assigned to these arguments.

\subsection{The Pangasinan Verbal Affix maN-}

The Pangasinan verbal affx maN- is typically used to indicate agent-oriented actions. ${ }^{(1)}$ Fidel de Amurrio (1970:148) mentioned that the verbal affix maN- is used along with roots that refer to the names of clothes (mansapatos 'to wear shoes', manpandong 'to wear a veil'), instruments (manpayong 'to use an umbrella', manmakinilya 'to use a typewriter', manpyano 'to play the piano'), and games or toys (mansipa 'to play sipa (a kind of foot ball)', mansungka 'to play sungka') to indicate actions that use these accessories and instruments.

In addition to the verb forms mentioned above, this verbal affix is also used along with verb roots related to cooking instead of oN-. Example of these forms include mangisa 'to sauté', mankalot 'to grill', manlambong 'to boil', manluto 'to cook', and manprito 'to fry'. It would be unusual for native speakers to produce verb forms like ongisa, onkalot, onlambong, onluto, and omprito.

Other verb roots that take the affix maN-pertain to the act of wearing or taking a piece of clothing off, which also signify actions or events that are performed by an agent. This can be observed in derived Pangasinan verbs such as mampales 'to change clothes', manlakseb 'to take one's shirt off', and manlabos 'to take one's pants or underwear off'.

Even though the maN- affix is typically used to indicate agent-oriented actions, the verbal affix can also be used along with verb roots that do not necessarily require volition such as the verbs mankogip 'to dream', manlikna 'to feel ill', and mansakit 'to get sick'.

Other than the semantic properties mentioned above, we should also consider the grammatical functions of the verbal affix maN-. There are verb roots that may be conjugated with the verbal affix maN- and not require internal arguments. These are traditionally referred to as intransitive verbs because the only argument that occurs with the verb is the grammatical subject, which can be assigned the semantic roles AGENT

\footnotetext{
(1) The term 'agent' is used here to refer to only volitional actor or doer of the action. It should be distinguished from the term 'experiencer' that, on the other hand, only experiences physical, psychological, cognitive, and mental state.
} 
A Closer Look at the Pangasinan Verbal Affixes maN- and oN-

(instigator of the action), THEME (the entity that undergoes change of state and change of location or possession, as well as the entity that undergoes the action initiated by agent), and EXPERIENCER (undergoes physical, psychological, cognitive, or mental state).

In the following examples, we have the derived verbs nanames, nangapo, and nanukok which assigned the semantic roles AGENT, THEME, and EXPERIENCER respectively to the grammatical subject, along with other similar type of derived verbs that select only one argument.

\begin{tabular}{|c|c|c|c|}
\hline \multirow[t]{11}{*}{ (3) } & Nanames & ak & dayat \\
\hline & Nan-ames & ed & dayat \\
\hline & Prf.AgF-bathe & 1Sg.ABS LocMark & sea \\
\hline & \multicolumn{3}{|c|}{ 'I bathed in the beach.' } \\
\hline & mambatik & 'to run' & \\
\hline & mambilay & 'to live' & \\
\hline & manabet & 'to meet in the middle' & \\
\hline & manakar & 'to walk' & \\
\hline & manalagey & 'to stand' & \\
\hline & manamot & 'to hide' & \\
\hline & mansalita & 'to talk' & \\
\hline \multirow[t]{6}{*}{ (4) } & Nangapo & lay & programa \\
\hline & Nan-gapo & $l a=y$ & programa \\
\hline & Prf.ThF-start & already $=$ FCNMarkSg & program \\
\hline & 'The program has & ady started.' & \\
\hline & mansara & 'to close down' & \\
\hline & mantapos & 'to end' & \\
\hline \multirow[t]{7}{*}{ (5) } & Nanukok & ak & \\
\hline & Nan-ukok & ak & \\
\hline & Prf.ExpF-cough & 1Sg.ABS & \\
\hline & mambilay & 'to live' & \\
\hline & maninawa & 'to live comfortably' & \\
\hline & mansakit & 'to get sick' & \\
\hline & manukok & 'to cough' & \\
\hline
\end{tabular}

The second category includes derived verbs with maN- + root that select one internal argument. The grammatical subject is assigned the semantic role AGENT or EXPERIENCER while the internal argument is assigned the semantic role THEME.

In the following examples, we have the verb nambalkot, followed by other related verbs, which assign the semantic role AGENT to the grammatical subject bii 'woman' and THEME to the internal argument regalo 'gift'. Both nankogip and mangaro assign the 


\section{Francisco C. Rosario, Jr.}

semantic role EXPERIENCER to the grammatical subject ak 'I' and THEME the internal arguments anyani 'ghost' and bii 'woman'.

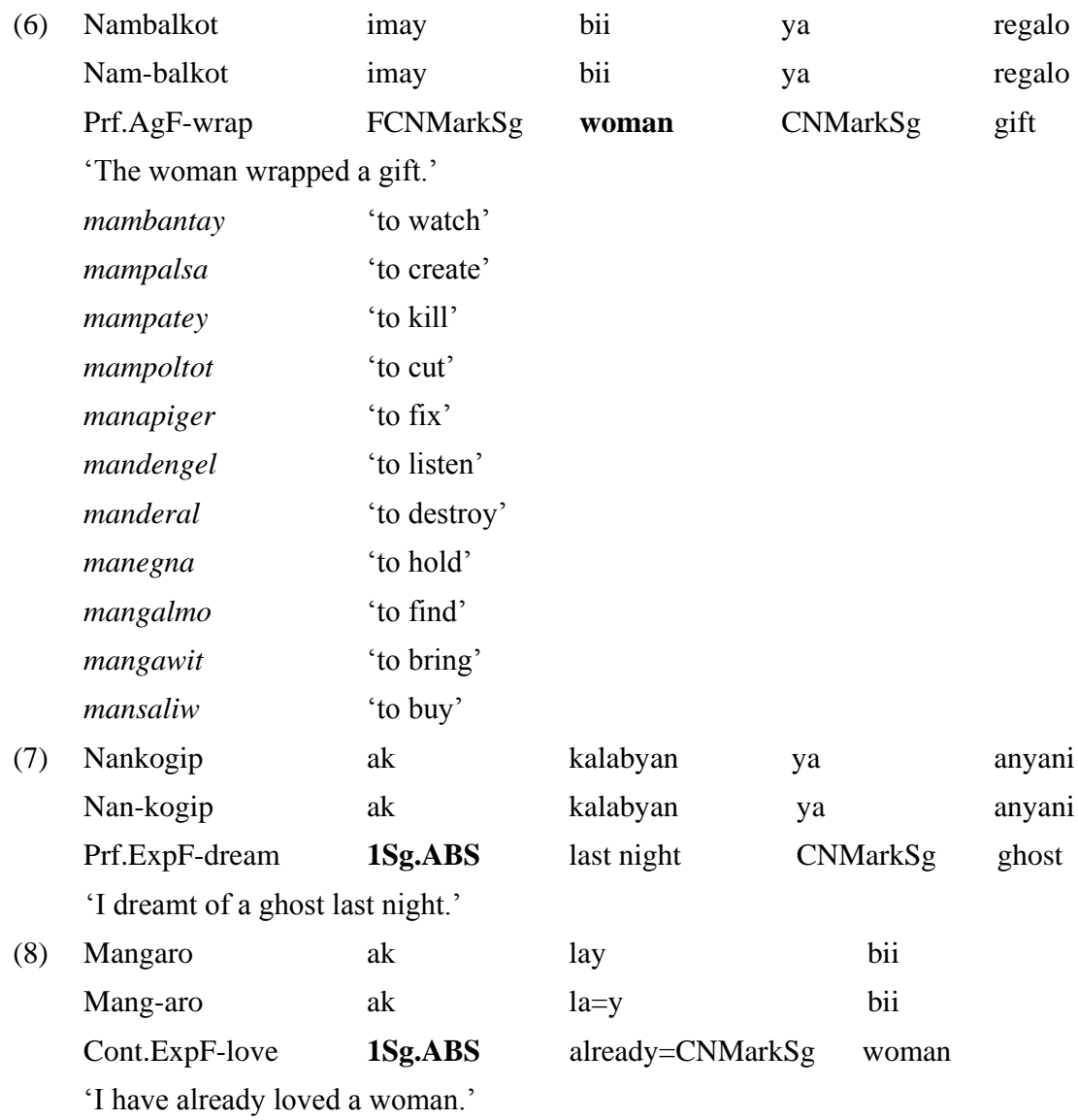

Other derived forms under this category assign the semantic role AGENT to the grammatical subject while the internal argument is assigned the semantic role LOCATION (the actual location where an action or event was performed). Other related semantic roles that may be assigned to the internal arguments include SOURCE (the point of origin) and GOAL (the endpoint).

For example, the verbs manayam and nanlapu would require not just a grammatical subject with the semantic role AGENT, but also internal arguments tagey 'upstairs' and abong mi 'our house' that are assigned the semantic roles LOCATION and SOURCE, respectively.
(9) Manayam$$
\text { tayod }
$$
tagey
Man-ayam
tayo $=\mathrm{d}$
tagey
Cont.AgF-stay
1PIIncl.ABS=LocMark
upstairs 
A Closer Look at the Pangasinan Verbal Affixes maN- and oN-

'We will stay upstairs.'

\begin{tabular}{|c|c|c|c|c|}
\hline Nanlapu & ak & ed & abong & $\mathrm{mi}$ \\
\hline Nan-lapu & ak & ed & abong & $\mathrm{mi}$ \\
\hline Prf.AgF-come from & 1Sg.ABS & LocMark & house & 1Pl.GEN \\
\hline
\end{tabular}

Lastly, we also have verb roots that take the affix maN- and select two internal arguments. The verbs manpawit 'to send' and mangiter 'to give' would require a grammatical subject which is assigned the semantic role AGENT and two internal arguments that take the semantic roles THEME and RECIPIENT (the entity that acquires or receives the action initiated by the AGENT). This is illustrated in the example below where AGENT is assigned to the grammatical subject gobyerno 'government', THEME to tulong 'help' and RECIPIENT to totoo 'people'.

\begin{tabular}{|c|c|c|c|c|}
\hline Naniter & ya & tulong & so & gobyerno \\
\hline Nan-iter & ya & tulong & so & gobyerno \\
\hline Prf.AgF-give & CNMarkSg & help & FCNMarkSg & government \\
\hline ed & totoo & & & \\
\hline ed & totoo & & & \\
\hline OBLMark & people & & & \\
\hline
\end{tabular}

\subsection{The Pangasinan Verbal Affix oN-}

A quick survey of the verb roots that co-occur with the Pangasinan verbal affix oNwould refer to this as the affix that form the 'verbs of becoming'. Certain semantic classes of verb roots take the verbal affix oN- to signal a change of state. This change of state covers color or visual state as in ombalanga 'to become red', onduyaw 'to become yellow', omputi 'to become white', ondeket 'to become black or dark', ombilonget 'to become dark', onliwawa 'to become bright', and onsileng 'to become shiny'. Verb roots pertaining to the change in texture also use the affix oN- instead of maN- as can be observed in ongasal 'to become rough', onkinis 'to become smooth', onawet 'to become hard', and onlemek 'to become soft'.

Verb roots related to nature also take the affix oN- as can be observed in the following: onagew 'to become sunny', ombagyo 'to have a typhoon', ondelap 'to flood', onuran 'to rain', ontayaketek 'to drizzle', and onyegyeg 'to have an earthquake'.

Meanwhile, looking at the grammatical functions of this verbal affix, the categories of verbs conjugated with the verbal affix oN- are not totally different from the ones with the verbal affix maN-. The first category includes derived verbs with oN- + root that do not select any internal argument. The verbs only co-occur with the grammatical subject, which 


\section{Francisco C. Rosario, Jr.}

can be assigned the semantic role AGENT or THEME depending on the derived verb. To illustrate, the verb assigns AGENT to the grammatical subject of sentence (12) aso 'dog' while THEME is assigned to bukel 'seed', which is the grammatical subject of sentence (13).

\begin{tabular}{|c|c|c|c|c|}
\hline \multirow[t]{10}{*}{$(12)$} & Tinmewek & so & aso & \\
\hline & T-inm-ewek & so & aso & \\
\hline & Prf.AgF-look down & FCNMarkSg & $\operatorname{dog}$ & \\
\hline & \multicolumn{4}{|c|}{ 'The dog looked down.' } \\
\hline & onlimata & \multicolumn{3}{|c|}{ 'to open one's eyes' } \\
\hline & onlukso & \multicolumn{3}{|l|}{ 'to jump' } \\
\hline & onorong & \multicolumn{3}{|c|}{ 'to go to market' } \\
\hline & onsabi & \multicolumn{3}{|c|}{ 'to arrive' } \\
\hline & onsileng & \multicolumn{3}{|c|}{ 'to become shiny' } \\
\hline & ontangay & \multicolumn{3}{|l|}{ 'to look up' } \\
\hline \multirow[t]{12}{*}{ (13) } & Tinmubo & la & imay & bukel \\
\hline & T-inm-ubo & la & imay & bukel \\
\hline & Prf.ThF-grow & already & FCNMarkSg & seed \\
\hline & 'The seed already gr & & & \\
\hline & onawet & \multicolumn{3}{|c|}{ 'to become hard' } \\
\hline & ondalan & \multicolumn{3}{|l|}{ 'to pass by' } \\
\hline & onelet & \multicolumn{3}{|c|}{ 'to become tight' } \\
\hline & oniwas & \multicolumn{3}{|l|}{ 'to avoid' } \\
\hline & onlemek & \multicolumn{3}{|c|}{ 'to become soft' } \\
\hline & onletaw & \multicolumn{3}{|l|}{ 'to appear' } \\
\hline & ompatnag & \multicolumn{3}{|c|}{ 'to become apparent' } \\
\hline & ontubo & \multicolumn{3}{|l|}{ 'to grow' } \\
\hline
\end{tabular}

The other category includes derived verbs with oN- + root that select only one internal argument. The derived verbs signify an action or event that require an entity that deliberately performs the action (AGENT) and another entity that receives or is affected by the action (THEME). In sentence (14) kami 'we' is assigned the semantic role AGENT while pelikula 'movie' is the THEME.

$\begin{array}{llll}\text { (14) Binmantay } & \text { kami } & \text { ya } & \text { pelikula } \\ \text { B-inm-antay } & \text { kami } & \text { ya } & \text { pelikula } \\ \begin{array}{l}\text { Prf.AgF-watch } \\ \text { 'We watched a movie.' }\end{array} & \text { CNMExcl.ABS } & & \text { movie } \\ \text { ondengel } & \text { 'to listen' } & & \\ \text { oninom } & \text { 'to drink' } & & \end{array}$


A Closer Look at the Pangasinan Verbal Affixes maN- and oN-

$\begin{array}{ll}\text { onkerew } & \text { 'to ask for something' } \\ \text { onketket } & \text { 'to bite' }\end{array}$

Other verb forms under this category assign AGENT to the grammatical subject while the internal argument is assigned the semantic role LOCATION. In sentence (15), Mayor $\mathrm{Al}$ is assigned the semantic role AGENT while LOCATION is assigned to taytay 'bridge'.

\begin{tabular}{|c|c|c|}
\hline (15) Onakar & si & Mayor Al \\
\hline On-akar & si & Mayor Al \\
\hline Cont.AgF & FPNMarkSg & Mayor Al \\
\hline \multicolumn{3}{|c|}{ 'Mayor Al will walk in the middle of the bridge. } \\
\hline onabet & \multicolumn{2}{|c|}{ 'to meet someone somewhere' } \\
\hline ondago & \multicolumn{2}{|l|}{ 'to aproach' } \\
\hline ondalaw & \multicolumn{2}{|l|}{ 'to visit' } \\
\hline onla & \multicolumn{2}{|l|}{ 'to go' } \\
\hline onloob & \multicolumn{2}{|l|}{ 'to enter' } \\
\hline onsempet & \multicolumn{2}{|l|}{ 'to go home' } \\
\hline onsingger & \multicolumn{2}{|l|}{ 'to go near' } \\
\hline ontaboy & \multicolumn{2}{|l|}{ 'to jump into' } \\
\hline
\end{tabular}

It is observed in this section that although the verbal affixes maN- and oN- are classified as "subjective verbal forms" or "active focus affixes" because the doer or the initiator of the action is the center of attention in the sentence or the grammatical subject (AGENT), other derived verbs can also focus arguments with different semantic roles - THEME and EXPERIENCER. It is also important to note that these verbal affixes do not equally occur with all Pangasinan verb roots. There are verb roots that can occur with maN- but not with $\mathrm{oN}$ - as observed in the specific semantic classes of verb roots presented above.

\section{The Semantic Contrasts of maN- and oN-}

As can be observed in the previous sections, both the Pangasinan verbal affixes maNand oN- share similar semantic and grammatical functions. Both affixes can be used along with verb roots to derive verbs that focus arguments that take the semantic role AGENT or THEME, but one distinct difference is that the semantic role EXPERIENCER is assigned only to derived verbs with the affix maN-.

This section presents the specific semantic properties that illustrate the semantic contrasts between the Pangasinan verbal affixes maN- and oN- when used along with the same set of verb roots. It is interesting to note, however, that although some verb roots can take both verbal affixes and appear to be semantically similar, a native speaker can still determine the semantic difference between the two forms. Semantic differences between these derived verb forms which can be observed specifically on how the event occurred, 


\section{Francisco C. Rosario, Jr.}

how the action was performed, as well as the number of participants involved.

\section{$4.1 \mathrm{maN}$ - [+reciprocal]; oN- [-reciprocal]}

With regard to the use of verbal affix maN-, Fidel de Amurrio (1970) said that it can be used in both transitive and intransitive verbs "to indicate an action performed by many subjects." Although he is correct in saying that the use of this affix requires a plural subject, he also provided examples which actually only require a singular subject. In the case of the verb manloob 'to enter' in sentence (16), the grammatical subject ak ' $\mathrm{I}$ ' is singular. The same can be observed in manyurong 'to be sitted' and manalagey 'to be standing' when used in sentences.

\begin{tabular}{|c|c|c|c|}
\hline (16) Manloob & ak & ya & kiew \\
\hline Man-loob & ak & ya & kiew \\
\hline ContF.bring inside & 1Sg.ABS & CNMarkSg & wood \\
\hline
\end{tabular}

However, using the same observation that plural subjects are involved in verbs with the affixes maN- and oN-, we can take into consideration the following derived verbs.

$\begin{array}{llll}\text { maN- } & & \text { oN- } & \\ \text { man-abot } & \text { 'to meet halfway' } & \text { onabot } & \text { 'to reach the destination' } \\ \text { man-akdol } & \text { 'to sleep together' } & \text { onakdol } & \text { 'to sleep beside a person' } \\ \text { man-arap } & \text { 'to face each other' } & \text { onarap } & \text { 'to face front' } \\ \text { mansanib } & \text { 'to join together' } & \text { onsanib } & \text { 'to join another person or group' }\end{array}$

Even though the derived verbs signify the same action expressed in the verb, there is still a noticeable semantic contrast between these derived forms. A native speaker would identify that the resulting verb using maN- would involve reciprocality - that is, something is done mutually between two or more people. Using one of the examples above, man-akdol which means 'to sleep beside each other' is distinct from onakdol 'to sleep beside a person' because the first form implies two persons that mutually perform the act of sleeping beside each other. The second form, on the other hand, implies that only one person is actively involved in performing the act.

\section{$4.2 \mathrm{maN}$ - [+repetitive]; oN- [-repetitive]}

Other than reciprocality, the verbal affixes maN- and oN-also differ on how the event occurred or how the action was performed. Using Fidel de Amurrio's observation (1970:146), the use of the verbal affix maN- "indicates repetitious performance or occurrence of an action or event". It can also be used to indicate actions done with longer duration compared to the derived forms with the verbal affix oN-.

$\begin{array}{lll}\text { maN- } & \text { oN- } & \\ \text { mandengel 'to listen' } & \text { ondengel } & \text { 'to listen' } \\ \text { man-inom 'to drink' } & \text { oninom } & \text { 'to drink' }\end{array}$


A Closer Look at the Pangasinan Verbal Affixes maN- and oN-

$\begin{array}{llll}\text { mankerew } & \text { 'to ask for something' } & \text { onkerew } & \text { 'to ask for something' } \\ \text { man-akar } & \text { 'to go around walking' } & \text { onakar } & \text { 'to walk' } \\ \text { man-amot } & \text { 'to go around hiding' } & \text { onamot } & \text { 'to hide' } \\ \text { manbatik 'to go around running' } & \text { onbatik } & \text { 'to run' } \\ \text { man-elek 'to laugh' } & \text { onelek } & \text { 'to laugh' } \\ \text { man-irong 'to sit for a longer period' } & \text { onirong } & \text { 'to sit' } \\ \text { manliber 'to go around the area' } & \text { onliber } & \text { 'to go around' } \\ \text { manlukso 'to jump' } & \text { onlukso } & \text { 'to jump' } \\ \text { man-ogip 'to sleep' } & \text { onogip } & \text { 'to sleep' }\end{array}$

In the case of the derived verbs mandengel and ondengel, the former signifies an event that is to be performed for a longer period compared to the latter which refer to a shorter activity. The verb manliber signify an action that is performed longer and repeatedly while onliber signify an action that may be performed once and in a shorter period of time.

\section{3 maN- [+deliberate]; oN- [-deliberate]}

In the following list of derived verbs that take maN- and oN-, the semantic difference can be observed in the degree of effort exerted in performing these actions. Verbs with maN- indicate actions that are performed with effort, intentionally, or deliberately by the subject compared to the derived forms that take oN- that "indicate an action of little activity, effort, duration or importance" (Fidel de Amurrio, 1970: 143).

\begin{tabular}{llll} 
maN- & \multicolumn{2}{c}{ oN- } \\
manbalor & 'to coil something around' & onbalor & 'to coil around' \\
manlereg & 'to let something settle & onlereg & 'to be settled at the \\
& at the bottom of a liquid' & & bottom of a liquid' \\
man-olit & 'to repeat something' & onolit & 'to be repeated' \\
mansara & 'to close or close down' & onsara & 'to become closed' \\
mansilew & 'to use light' & onsilew & 'to be lit' \\
man-uksoy & 'to tidy things up' & onuksoy & 'to become tidy'
\end{tabular}

\section{Conclusion}

Upon closer examination of the Pangasinan verbal affixes maN- and oN-, we are able to identify the semantic and grammatical functions of both affixes. Both affixes are generally used to signify agent-oriented actions, but we have also observed that the derived forms also indicate actions that are not intentionally, volitionally, or deliberately performed. The semantic classes of verb roots that are compatible with maN- and oN- also differ. We have observed a regular correspondence between the affix maN- and verb roots that refer to the names of instruments, games, and accessories, as well as those that pertain to cooking and wearing and taking off a piece of clothing. The oN- affix, on the other hand, is consistently 


\section{Francisco C. Rosario, Jr.}

compatible with verb roots that pertain to the change of state and nature-related phenomenon.

We also see the complexity of Pangasinan verbal morphology. It is observed that the identified grammatical and semantic functions of the verbal affixes are determined by the combined meanings of the affix and the root. The affix indicates the grammatical category of the word, however the type of arguments that co-occur with the derived form is dependent on the inherent meaning of the root. For example, the verb roots ukok, sakit, and bilay are inherently intransitive so the resulting derived verbs are still intransitive even after using the affix maN-. On the other hand, the meaning of the derived verbs may also depend on the affix. This one is observed particularly in the case of verb roots that may take both affixes (see mandengel and ondengel in section 4.2 of this paper). These forms serve as proof that difference in form signifies difference in meaning, and that the semantic distinction between the same set of derived verbs, no longer depends on the semantic properties of the verb root, but rather on the semantic properties of the verbal affix used.

\section{References}

Ballard, L. Jr. 1974. The semantics of Inibaloi verbal affixes [J]. Lingua, 34:181-218.

Benton, R. A. 1971. Pangasinan reference grammar [M]. Honolulu: University of Hawaii Press.

Fidel de Amurrio, Rev. 1970. Pangasinan grammar [M]. Pangasinan: Bugallon.

Haegeman, L. 1994. Introduction to government and binding theory [M]. Oxford: Blackwell.

Magat, B. 1970. Case and number in English and in Pangasinan [D]. Unpublished master's thesis. Quezon City: University of the Philippines Diliman.

Mendoza, I. 1965. Aspect in English and Pangasinan verbs: A contrastive analysis [D]. Unpublished master's thesis. Quezon City: University of the Philippines Diliman.

Rosario, F. Jr. 2013. Subcategorization of Pangasinan verbs [D]. Unpublished master's thesis. Quezon City: University of the Philippines Diliman.

Schachter, P. \& Otanes, F. T. 1972. Tagalog reference grammar [M]. Berkeley: University of California Press.

Simons, G. F. \& Fennig, C. D. 2017. Ethnologue: Languages of the world, 20th ed. Dallas, Texas: SIL International.[OL] Online version: http://www.ethnologue.com. 